\title{
Japanese CEOs Cross-Cultural Management of Customer Value Orientation in India
}

\begin{tabular}{|r|l|}
\hline Journal: & Management Decision \\
\hline Manuscript ID & MD-06-2020-0776.R1 \\
\hline Manuscript Type: & Original Article \\
\hline Keywords: & $\begin{array}{l}\text { Cross-cultural management, Qualitative research, Japan, India, customer } \\
\text { value orientation }\end{array}$ \\
\hline
\end{tabular}

\section{SCHOLARONE \\ Manuscripts}




\section{ABSTRACT:}

The purpose of this paper is to develop understanding of cross-cultural issues relating to the experience and implications of an elite grouping of Japanese CEOs customer value orientations (CVO) within Japanese firms operating in India. The paper underlines that there is a propensity for East-West comparisons and in contrast the argument contributes to the under-examined area of research on East Asian/South Asian comparative studies.

Semi-structured interviews were employed to generate narratives that provided rich and novel insights into the lived experience of Japanese CEOs working in Indian contexts and in relation to CVO. An inductive framework was employed in order to develop a more in-depth understanding of Japanese CEO CVO in Indo-Japanese empirical settings.

The data analysis identified a number of shared themes that influence CVO practice in the IndoJapanese context. The findings develop an awareness of cross-cultural managementâ $€^{\mathrm{TM}} \mathrm{s}$ (CCM) in relation to the under-explored area of the Indo-Japanese dyad.

The paper develops CCM perspectives towards a more in-depth conceptualization of Japanese CEO perceptions on CVO practice in India. This is also of potential relevance to wider foreign investors not only Japanese businesses. The sample respondents â $€$ "Japanese CEOS working in India constitute a small and elite group. The lead author, having experience as a CEO of a Japanese firm was able to use convenience sampling to access this difficult to access group. In addition, also stemming from the convenience aspect, all the respondents were in the manufacturing sector. The study was deliberately targeted and narrowly focused for this reason and does not claim automatic wide generalizability to other employee strata or industry however other sectors and employees may recognize resonance. This identified gap provides space for future studies in varying regional, national and sector contexts.

The paper identifies implications for CCM training and Indo-Japanese business organization design.

Use and acceptance of the enhanced research paradigm could support diversity in research and knowledge production with implications for research, teaching and future policy makers.

The cross-cultural study is original in that it contributes to CCM literature by providing a rare IndoJapanese (sic East Asian: South Asian) comparative study. It provides an uncommon granular appreciation of the interaction of these cultures in relation to CVO. In addition it secures rare data from an elite Japanese CEOs of manufacturing sector businesses. 


\title{
Japanese CEOs Cross-Cultural Management of Customer Value Orientation in India
}

\begin{abstract}
Purpose: The purpose of this paper is to develop understanding of cross-cultural issues relating to the experience and implications of an elite grouping of Japanese CEOs customer value orientations (CVO) within Japanese firms operating in India. The paper underlines that there is a propensity for East-West comparisons and in contrast the argument contributes to the under-examined area of research on East Asian/South Asian comparative studies.
\end{abstract}

Design/ methodology/ approach: Semi-structured interviews were employed to generate narratives that provided rich and novel insights into the lived experience of Japanese CEOs working in Indian contexts and in relation to CVO. An inductive framework was employed in order to develop a more in-depth understanding of Japanese CEO CVO in Indo-Japanese empirical settings.

Findings: The data analysis identified a number of shared themes that influence CVO practice in the Indo-Japanese context. The findings develop an awareness of cross-cultural management's $(\mathrm{CCM})$ in relation to the under-explored area of the Indo-Japanese dyad.

Research limitations/ implications: The paper develops CCM perspectives towards a more indepth conceptualization of Japanese CEO perceptions on CVO practice in India. This is also of potential relevance to wider foreign investors not only Japanese businesses. The sample respondents - Japanese CEOS working in India - constitute a small and elite group. The lead author, having experience as a CEO of a Japanese firm was able to use convenience sampling to access this difficult to access group. In addition, also stemming from the convenience aspect, all the respondents were in the manufacturing sector. The study was deliberately targeted and narrowly focused for this reason and does not claim automatic wide generalizability to other employee strata or industry however other sectors and employees may recognize resonance. This identified gap provides space for future studies in varying regional, national and sector contexts.

Practical implications: The paper identifies implications for CCM training and Indo-Japanese business organization design.

Social implications: Use and acceptance of the enhanced research paradigm could support diversity in research and knowledge production with implications for research, teaching and future policy makers.

Originality/value: The cross-cultural study is original in that it contributes to CCM literature by providing a rare Indo-Japanese (sic East Asian: South Asian) comparative study. It provides an uncommon granular appreciation of the interaction of these cultures in relation to CVO. In addition, it secures rare data from an elite Japanese CEOs of manufacturing sector businesses.

Keywords: Cross-cultural management, India, Japan, customer value orientation. 


\section{Introduction}

The purpose of this paper is to explore cross-cultural issues which underpin Japanese CEO customer value orientation (CVO) whilst running Japanese manufacturing companies located in Indian contexts. In this paper, we develop an argument which defines CVO as a product and fusion of three terms: customer value creation, customer orientation and customer satisfaction, and these terms are explored and contextualized in the discussion below. Moreover, the study underlines that while cross-cultural management (CCM) scholarship has traditionally focused on contemporary national dimensions of culture (Sackmann, 2020), wider historical and cultural contextual factors may also play an important role in influencing international business practice (Earley, 2006; Tsui et al., 2007). Accordingly, the study recognizes that, in order to open new lenses on CCM in general, and the under-researched area of Indo-Japanese business setting dynamics in particular, it will be timely and useful to consider alternative conceptual framings (Patel, 2017; Romani et al., 2018). For instance, many extant studies undertake an East-West gaze (Urry and Larsen, 2011) as the point of analysis. However, there are fewer studies which have undertaken an East Asian-South Asian (sic: Japanese-Indian) comparison and this also represents a novel contribution of the study. The above novel points lead to the following research question:

RQ: What cross-cultural factors inform and facilitate CVO of Japanese CEOs in India?

The paper is structured as follows. The study first defines and reviews the concept of CVO in the context of Indo-Japanese CCM. Subsequently, the adopted inductive methodology is explained and the methods used outlined. A series of interview findings - analysed using thematic analysis - are presented and discussed. Finally, insights and implications on Indo-Japanese international business at the CEO level in relation to $\mathrm{CVO}$ are stated. 


\section{Literature review}

Customer value orientation (CVO) - synthesizing a meta-philosophy

Corporate success, often conventionally measured by profits, is inter alia influenced and differentiated by CVO and this idea has been gaining ground since the 1990s (Fornell et al, 2016; Khalifa 2004; Kohli and Jaworski, 1990; Kordupleski and Laitamaki, 1997; Kumar et al, 2010; Narver and Slater, 1990; Sorescu and Sorescu, 2016; Turpin, 1994). Herein, the study notes that the older and more prevalent concept of 'customer satisfaction' (the relative difference between pre-purchase expectations and the post-consumption evaluation) is recognized to be strongly related to customer value (Terpstra and Verbeeten, 2014; Woodruff, 1997), even if not interchangeably the same (Butz and Goodstein, 1996). Within companies, the focus of the marketing function has commonly been on the customer and the customer-centric focus has been further strengthened (Zinser and Brunswick, 2016) as concepts such as service dominant logic have evolved and risen to prominence (Vargo and Lusch, 2008). Abdullah and Siraj (2017) also point out that customer centricity has of course been heightened by the advent of the Internet and social media. Proactive and responsive customer orientation creates superior value for the customer (Blocker et al., 2011), and also correlates positively to customer satisfaction (HennigThurau, 2004). The three aligned, yet distinctive, concepts of customer value (i.e. value added beyond the simple notion of price vs utility), customer satisfaction (i.e. the difference between expectation and post-purchase experience and customer/market orientation - essentially being customer focused) are sometimes referred to interchangeably or as a proxy (Kumar and Reinartz, 2016). Narver and Slater (1990) identify three component elements to market orientation and embed customer orientation with competitor orientation and inter-functional coordination. They 
suggest that, of these, customer orientation is the most important for customer value creation predicated on the idea that content customers ensure the sustainability of the business. Linking the above two ideas, Webster (1988) identifies the importance of customer orientation to customer satisfaction and the centrality of customer focus to the marketing concept. In the present study, this complexity in the area is represented in combined amalgam concept and over-arching construct of these triple terms - 'customer value orientation' (CVO) (see Figure 1). The resultant synthesized construct of CVO can be understood as: The propensity to serving the customer by driving satisfaction and value through either explicit or implicit intention.

Insert Figure 1 here

By recognizing the potent agglomerated construct of $\mathrm{CVO}$, the study can leverage on the understanding of this to illustrate how it operates in Indo-Japanese settings.

From an early point in the debate, Webster (1988) highlighted the importance of the individual senior manager to developing a customer orientation at the firm level. Equally, echoing Webster, the role of senior managers has been signalled as perhaps the most significant in influencing a customer foci (Kohli and Jawaorski, 1990). Therefore, the focus on Japanese CEOs in the present paper, underpins a significant role for these figures in relation to CVO. Having elaborated the concept of CVO, the argument now moves on to consider how CVO operates in Indo-Japanese CCM contexts, 


\section{Japanese CVO and the India context}

CVO plays an important role in Japanese management. For example, Ashta (2009) and Hosoda (2018) demonstrate that companies consider customer satisfaction as an important component of sustainable organizational evolution. Haron et al. (2015) found that in Japan CVO is considered as the top priority in relation to responsible and ethical dimensions of the firm - even at the level of small and medium enterprises and family businesses. As a result of this all-pervasive centrality accorded to CVO across management domains, customers in Japan are so pampered that they set the satisfaction benchmark for the rest of the world. Indeed, Melville (2000:70) asserts that in Japan: 'it is up to the company to produce what customers don't yet know what they want'. In addition, more contemporaneously, while it is recognized that many Japanese practices may have lost the global benchmark status they enjoyed in, for example, the 1990s, Japanese skills of customer satisfaction certainly remain well-established (Trompenaars and Hampden-Turner, 2012: 232), with the voice of the customer incorporated to ensure customer satisfaction (Griffin and Hauser, 1993). One well-known customer-oriented Japanese management practice is total quality management (TQM) (Butz and Goodstein, 1996). As part of TQM, Japanese companies such as Mitsubishi and Toyota pioneered quality function deployment (QFD) which leveraged the 'voice of the customer' for new product development, and indeed, TQM has also been widely adopted and employed in India although not without occasional adaptations (Bhat and Rajashekhar, 2009). Moreover, research by Blahova et al. (2015) showed that, though there are exceptions, overall, Japanese companies display a distinct trend of integrating customers into innovation processes as one of the key features of future growth and this is accompanied with ethical stances and positions. 
In contrast, Western convention often perceives customer-related matters in terms of compliance with the law and ethics rather than $\mathrm{CVO}$ and this convention has also undoubtedly also had some influence and impact in the India setting (Banks et al., 2016: 2218). Though companies such as Toyota and Sony have been emphasizing CVO for many years (Lander and Liker, 2007; Morgan and Liker, 2020), Turpin (1994: 324) found that, especially in the recessionary times of the 1990s, Japanese companies started focusing even extra effort and resources on the customer, adding value through employee selection, training and extensive communication: 'In Japan, a shared principle among marketers is that customer satisfaction is the primary management goal' (ibid). Turpin recommended an enhanced competition to meet and exceed customer expectations, instanced by activities such as, for example, customer involvement in new product development. This was also later observed by Blahova et al. (2015). An Indian case in point is the automobile manufacturer Maruti which is an example of success in India of Japanese CVO. Though the Japanese joint venture initial product quality was not very good, right from inception, the focus on customers satisfaction was high. Creating customer delight was a part of the company vision (Kazmi, 2009) and, consequently, the company achieved and has held market leader position for decades. Nevertheless, such Japanese CVO has generally been under-commented in relation to the economically important Indo-Japanese CCM contexts. This is the case even though Japanese investment in India is substantial - over the last decade the number of Japanese companies setting up operations in India has risen from 550 to 1441 companies (Invest India, 2020).

In addition, recent CCM literature has pointed at values and spiritual parallels between traditional Indian philosophy and contemporary Japanese management (Ashta et al., 2018; Chiarini et al., 2018; D’Costa, 2003; Kumar et al, 2011; Mathur, 2016). Typically, this work has identified the Buddhist influence on the Japanese work ethic and related management values, such 
as, for example, consensual decision-making, lean systems and quality consciousness and has acknowledged that Buddhism has its origins in Indian thought and history. Within CCM literature, Chevrier. (2003) pointed at such possibilities for confluence and conflict in the context of transnational project groups.. The practice of management was modernized in India with the setting up of the Indian Institutes of Management at Calcutta and Ahmedabad in 1959 and 1960, with support from leading American business schools: Sloan and Harvard respectively. Though IIM Calcutta houses a Management Center for Human Values (MCHV), when the author of this paper attended a one-year residential program in management, none in the author's cohort opted for an elective offered at the Center, choosing instead "mainstream" courses on finance and marketing, many taught by visiting professors from American universities. Thus, this American hegemony on Indian management students' conditioning remains even half a century later. As the founder of MCHV, Chakraborty (1991) wrote, there is a belief amongst Indian management students that:

\footnotetext{
"Whatever an affluent or technologically advanced society might say or do must be right and good; whatever might have been enshrined and institutionalized in an old but living culture, if it is economically poor or technologically backward, must be wrong and bad; therefore the path to the lost paradise lies in imitating the former and disowning the latter" ( $\mathrm{p} 24)$
}

Nevertheless, Mahajan and Sekiguchi (2016) concluded that even though American-based human resources (HR) practices are more prevalent globally (and widely adopted in India), it is actually Japanese HR practices that are likely to be more effective in India because of IndoJapanese cross-cultural similarities. 
However, in spite of these above observations little attention has been given to developing a deeper and contextualized understanding of cross-cultural value similarities and whether, or how, they might facilitate transfer of Japanese customer value creation techniques to India. Therefore, this paper addresses this 'management science-practice gap' (Bank's et al., 2016: 2205-2218) and additionally answers the growing call for CCM research to address contextual issues in developing holistic international business perspectives (Vaiman and Holden, 2015). Overall, there appears to be prima facie evidence for Japanese tools and techniques being successfully transplanted to India historically (Sparrow and Budhwar, 1997) grounded in cultural confluences. Having developed the conceptual terms of the argument, the paper now progresses to outline a methodology through which to examine the research question.

\section{Methodology}

In order to investigate the research question outlined above, the present work adopts an inductive approach. This is important because, in contrast, a recent review by Patel (2016) revealed that an overwhelming majority of published research in CCM has followed the objectivistinformed framework (e.g. Hofstede, Trompenaars and Hampden-Turner, GLOBE, Schwartz). Furthermore, within this canon, a meta-analyses of such research identified India and Japan as singletons, defying clustering (Ronen and Shenkar, 2013), and thereby suggesting specific uniqueness of these cultures. For studies on culture, Schedlitzki et al. (2017) identified the limits of an etic (outward looking), positivist approach and recommend instead emic (inward looking), qualitative research to overcome limitations of an Anglo-centric understanding of CCM issues. In the context of the present research question, this view is further reinforced by Garcia and Gluesing 
(2013) who recommended the use of qualitative methods in international contexts, advocating it especially in theory development situations (such as in the present paper), which seek to identify new structural elements, such as contextual CCM issues that underpin CEO Indo-Japanese CVO operations in India. There is a concern that established positivistic paradigms might not open the present researchers' line of vision to explore the field completely (Patel, 2017) and, moreover, given the elite nature of the respondent CEOs and the attendant difficult access issues and interview techniques required an inductive study seemed more appropriate (Moore and Stokes, 2012).

In-depth semi-structured interviews were conducted with very senior Japanese who had served or were serving CEOs at Indian subsidiaries. The study's primary author is fluent in Japanese, and conducting interviews in the respondents' native language facilitated a free flow of the respondents' expression of their lived experience (Welch and Piekkari, 2006) in India, contributing to robustness because of volume of data conveyed. Language fluency also facilitated interpretation of the data (Adams et al., 2017; Haynes, 2011). The sample size was expectedly small because of the express focus on elite, difficult to access senior market-makers and influencers (Moore and Stokes, 2012). The population of Japanese CEOs in India is de facto niche. This approach adhered to the established literature on elite interview (Moore and Stokes, 2012) which points up the challenges of engaging and accessing such powerful individuals. The seniority of the respondents adds robustness because of the information power (Malterud et al., 2016). Their insights of derived from deep, extensive experience and knowledge. Therefore, it is a novel contribution, and due to the network of the authorial team, that such rare and novel access was granted. 
Five senior Japanese CEOs were interviewed. The interviews each lasted over an hour and were followed up with questions over email. In three cases, the background to the research and preliminary interview discussion was conducted over dinner. This was a necessary protocol in Japanese cultural context. This was then followed up by extensive email exchange and telephone discussion/interviews. The respondents' profiles were: a) all male; b) from manufacturing industry, and, c) served/ serving in the Delhi area (India's north). The lack of respondent diversity is recognized as a limit of this study (King, 2004) and a reflection on the structural and institutional lack of diversity in Japanese firms and the manufacturing sector. The data were reviewed through thematic analysis (King, 2012). This generated main and secondary coding and allowed the data to be organized accordingly.

\section{Findings and Discussion}

In their interaction with India as their geographical territory, Japanese CEOs identified the customer value orientation (CVO) of the Indian customer. For example, when asked an open-ended question on their impressions of the Indian customer, Respondent 5 replied "I think Indian customers are very sensitive to price. I feel that they check the details that the value of goods is balanced with price very carefully". In a similar vein, Respondent 3 stated, "we were forced to evaluate quality of our products". Thus, having obtained an empirical reconfirmation from the CEO level of the importance of CVO contextualized to the Indian intercultural situation, the analysis delved to deeper cross-cultural factors within the Nested Spheres Model of Culture (Trompenaars \& Hampden-Turner, 2012) as found below. 


\section{An Indo-Japanese confluence of values of long-termism and harmony}

Within the data secured and analysed from the interviews two common cultural values emerged - long-termism and harmony (aligning in the Japanese context with Braun and Clarke, 2016). In relation to long-termism the Japanese CEO respondents commented on their experiences in India:

'I strongly believe that developing relations based on mid- to long-term vision is very important.' (Respondent 1 )

'In order to maintain long-term good relations without adhering to short termlarge profits, it was important to place top priority on establishing customer's trust by meeting its requirements. If a company can keep stable trustworthy clientele, it becomes possible to make investments for the future such as product development. Also, because the customer is like a partner, by incorporating its opinion value can be co-created. Also, in case the customer makes some difficult demand, because of the long trusting relationship it is possible to yield to such demand, and in turn the customer may look upon you favorably in the future. Thus, even for the customer it is useful to have a supplier that they can make extreme demands to in unusual circumstances. I don't wish to say that such long-term thinking is all correct, but it certainly facilitated Japan's economic growth, and I basically support it.' (Respondent 2)

It was evident from the respondents that the Japanese CEOs saw a role for harmony, inherent in their approach, as being present, pertinent to and relevant to the Indian context.

A second reported shared value was harmony.

'During the combined efforts in the multi-party team, I could feel a strong sense of harmony working with professors from academia.' (Respondent 3); 
'I had a subordinate deliver a Diwali (Indian festival) gift to the top officer. As a result, the officers started treating our cases favorably. At first, I wanted to denounce this in my anger, but gradually I came around to the view that this too is a manner in which "harmony" is created in the Indian way.' (Respondent 1);

'With Japanese customers, and of course there is variation from person to person, they will make demands that they feel are "reasonable". However, in the Indian scenario these "reasonable" demands often were difficult. Sandwiched between Japanese customers and Indian colleagues I had a tough time. Even so, through my explanations, fortunately, my Indian colleagues could gain an appreciation of my standpoint. This too is an example of harmony.' (Respondent 4).

These values are shown in Figure 3 below. Their presence, as noted above, in Japanese management is long known (cf Hatvany and Pucik, 1981). Nevertheless, the commonality of these values to traditional Indian philosophy is surfacing in emerging management literature (cf Ashta et al, 2018, 2019). Thus, the empirical data of this study can be seen as both informing and reinforcing traditional and emerging theory (Hambrick, 2007) however here within a hybrid context, i.e. Indo-Japanese business. Moving to a further nested sphere, three statements below point to geo-historical sources of this mindset in the Japanese CEOs:

'The Japanese are a homogenous race and have shared roots and shared mentality; even so our outlooks vary based on our upbringing and social environment. Accordingly, harmony became an important keyword ... we are a defenseless island nation endearing us to building trusting and helpful relations.' (Respondent 2) 


\begin{abstract}
'Japan is an island country surrounded by seas. We are an agrarian society. In other words, the Japanese are naturally stability seeking, and avoid uncertainty. Yesterday I had one partner, today the partner has changed. Yesterday was one strategy, today we adopt another and might change it further tomorrow - most people avoid such scenarios. That is the reason why we prefer to maintain long term relationships, with the same people, same clients and same organizations.' (Respondent 5)
\end{abstract}

'To me harmony comes with strong connotations of adjusting. In Japan we make various types of adjustments. The importance given to harmony in Japan is probably rooted in Buddhism. However, from an individual's standpoint, harmony is important in all kinds of relationships- family and relatives, friends (seniors and juniors), colleagues (seniors and subordinates) etc. - critically important for life value creation. People with discord probably have some character failings too, but overall will probably be lonely and low in happiness.' (Respondent 1)

Analysis of these three indicative statements suggests some generative mechanisms, namely: island nation motif, spiritual values (encompassing and echoing harmony and long termism), agrarian society, stability (kindred to harmony), and relationships. Indeed, it is perhaps important to highlight we are not insinuating perfect alliance across Japanese and Indian business cultures, but, instead, it is the degree of harmony that is successfully achieved aligning these two cultures. The mechanisms considered are catalysts for successful alignment. Harmony and the 'island nation' motif, in terms of seclusion from the world can be quasi-applied to India, also. For instance, it has the seas on three sides and mountainous geography on the continental links creating a kind of isolation (sub-continent) Meanwhile, the Indian ethos too is dominantly agrarian (Srinivas, 2012). Therefore, the transportability that was discussed earlier would stand because of 
the existence of similar mechanisms at the assumptions level of the Nested Spheres Model of Culture (Trompenaars \& Hampden-Turner, 2012).

However, the study also suggests that the island motif (seclusion) has been compromised and traditional values affected and that is why the mechanisms are impaired. The prevalence of the idea that modern (American) management philosophy is superior and contrarian ideas somehow belong to rural communities has been commented elsewhere (e.g. Trompenaars and Hampden-Turner; 2012: p 44). However, the Indian case has also been specifically contrasted by the other country in this research - Japan - where Japanese management practices are found more aligned to their culture (Chakraborty 1991; Srinivas 2012). This suggestion that external influence can thwart the underlying mechanisms (spiritual and wider values underpinning perspectives on $\mathrm{CVO}$ ) is also confirmed in the interview data generated. As Respondent 2 mentioned:

'In the past we had trusting relationships with our clients, at times extending supplies on credit. However, such long-term favoring relationships are unfortunately recently being questioned under the purview of compliance, and such customs are breaking down.' (Respondent 2)

Remaining within the compliance dynamic mentioned above, many of the international financial reporting standards are American influenced, and thus the study observes that subjugation to emerging external influence on Japan is seen as strangulating the historical mechanism for customer value orientation. Combining the Charaborty (1991) observation on what has happened in India and current- times Respondent 2 observation of what is beginning to happen in Japan, the study inadvertently discovers that continuing American influences - for example, on global compliance standards - are a threat to traditional customer value orientation operationalizing 
mechanisms, and accordingly the grand challenges confronting especially academics (Banks et al., 2016). This needs to change in order to conserve the traditional mechanisms discovered.

\section{Implications for theory}

Through the above discussion, the study identified common Indo-Japanese values such as harmony and long-termism that facilitate CVO. Such findings contribute to theory not by building new theory, but rather in the spirit of reinforcing extant theory through novel additional empirical evidence (cf. Hambrick, 2007). Importantly, by looking at assumptions shaped by contextual factors such as island motif and agrarian society heritage, the discussion mined factors other than cultural values - in this case geography and history - that add to the growing opinion among CCM scholars that CCM research remit extends deeper than notions of national cultural values (cf Vaiman and Holden, 2015).

While, the seminal remit of CCM scholarship originated from a study of language (cf Hall, 1960), in recent decades there has been a strong shift and focus to national dimensions of culture such as found in the Hofstede (1983) and Schwartz (1999) studies. However, there is a growing call that in the vein of envsioning a more nested view of culture. This invites and calls for CCM studies beyond the usual East-West comparisons and looks for East Asian/South Asian comparisons such as has been considered herein. In addition, contextual factors, such as history and geography, that create assumptions also need to heighthened to the common remit of CCM research and this study, through the alternative paradigm unearthed such important assumption forming contextual factors as illustrated in Figure 2.

Insert Figure 2 here 
Additionally, the contribution to India-Japan international business dyad CVO scholarship can be seen in Figure 3. In the spirit of Hambrick (2007) that contribution towards theory is in the form of reinforcing extant understanding, the importance of harmony and long-termism as values that promote CVO implementation surfaced again. The greater contribution was the opportunity to secure data on the deeply rooted contextual factors, such as common agrarian heritage and the island nation motifs that had eluded CCM scholar's observations on Indian and Japanese contexts.

Insert Figure 3 here

Implications for practice

CCM theory development impacts on CCM training programmes. Under the classical positivist derived national dimensions of culture, India and Japan are placed in two separate world cultural clusters. For example, the Schwarz (1999) model locates Japan in the English-Speaking cluster (sic) and India in the Far East cultural cluster. Inferring from such extant literature, a crosscultural trainer in Europe for example, might be tempted to think of separate programmes for executives dealing with India and those with Japan. However, the commonalities emerging from the current study presents an argument to re-think extant training programmes.

Similarly, the current study would have implications for organization design. There is a tendency in international business departments to develop separate administrative sections for dealing with groupings of countries, and under the Schwartz classification, an international 
business in Italy might well consider placing Japan and the UK under the same administration section, while putting India and China together in another section. However, under the above emerging implications that India and Japan in fact have more in common that has surfaced through conventional research methods, Organization design could well be reconsidered to manage India and Japan under a common administrative section.

\section{Implications for society}

The study finds two hitherto unexplored factors - island geography and historical agrarianism - as converging factors of cultural importance to the India-Japan CCM CVO dyad. Such a deeper understanding of at the assumptions level (refer also to Figure 2 for visualization) paves the way for heightened appreciation of congruence between the two countries. Under extant scholarship, religion and language held as the most important predictors of world cultural clusters (Ronen and Shenkar, 2013), and when geography is considered it is about geographic neighbourhood, rather than geography typology (island in this case). However, the present study lends support for the emerging theoretical idea of an India-Japan cultural cluster (cf Ashta et al, 2018, 2019), which in turn would facilitate international business flows (Ronen and Shenkar, 2013).

However, this study can endeavor to move thinking beyond the linear and normative within international management practice. For example, placing great emphasis around central factors such as harmony and long-termism can draw attention away from managerialist obsessions that focus more routinely within measuring productivity, performance and profit (amongst other positivist/quantitative guidelines). Bringing deeper discussion through key mechanisms such as 
spiritual values and other difficult to quantify, but pivotal, aspects keeps these important and essential elements alive when considering how to successfully manage within overseas cultures.

\section{Conclusion}

The study considered the RQ: What cross-cultural factors inform and facilitate CVO of Japanese CEOs in India? A literature review served to establish the urgency and importance of the topic and also define CVO, an important potential contributing area for Japan business flow to India. Deploying thematic analysis identified common cultural values such as harmony and long-termism that informed conventional and emerging CCM theory in a novel and more nuanced manner. However, what newly surfaced to the CCM domain was commonality of the island motif and agrarian industrial history. The study raises hope that such emerging commonalities in theory will percolate to business managers and public policy makers, facilitating international business flows from Japan to India.

Note 1: There is no conflict of interest.

Note 2: The study followed ethical guidelines found in The Research Ethics Guidebook: a resource for social scientists (http://www.ethicsguidebook.ac.uk) 


\section{References}

Abdullah, \& Siraj, S. (2017). Customer lifetime value creation through customer engagement in social media. International Journal of Management and Development Studies, 6(10), 44-55.

Adams, T. E., Ellis, C., and Jones, S. H. (2017). Autoethnography. The International Encyclopedia of Communication Research Methods, 1-11.

Ashta, A. (2009, December). A Force Called Team CSR India. Hitachi Review, 58(6), 306-308.

Ashta, A., Stokes, P., and Hughes, P. (2018). Change management in Indo-Japanese crosscultural collaborative contexts: Parallels between traditional Indian philosophy and contemporary Japanese management. Journal of Organizational Change Management, 31(1), 154-172.

Ashta, A., Stokes, P., and Hughes, P. (2019). Logic or smiles? International talent management across advanced and emerging economic contexts-Japanese expatriates' cross-cultural communication friction in India. In Research Handbook of International Talent Management. Edward Elgar Publishing.

Banks, G. C., Pollack, J. M., Bochantin, J. E., Kirkman, B. L., Whelpley, C. E., and O’Boyle, E. H. (2016). Management' s science-practice gap: A grand challenge for all stakeholders. Academy of Management Journal, 59(6), 2205-2231.

Bhat, K. S., \& Rajashekhar, J. (2009). An empirical study of barriers to TQM implementation in Indian industries. The TQM Journal, 21(3), 261-272.

Blahova, M., Haghirian, P., and Palka, P. (2015) "Major factors affecting contemporary Japanese business environment", International Journal of Productivity and Performance Management, Vol. 64 Issue: 3, pp.416-433

Blocker, C. P., Flint, D. J., Myers, M. B., and Slater, S. F. (2011). Proactive customer orientation and its role for creating customer value in global markets. Journal of the Academy of Marketing Science, 39(2), 216-233.

Braun, V., and Clarke, V. (2016). (Mis) conceptualising themes, thematic analysis, and other problems with Fugard and Potts'(2015) sample-size tool for thematic analysis. International Journal of Social Research Methodology, 19(6), 739-743.

Butz, H. E., and Goodstein, L. D. (1996). Measuring customer value: gaining the strategic advantage. Organizational Dynamics, 24(3), 63-77. 
Chakraborty, S. K. (1991). Management by Values: Towards Cultural Congruence, Oxford University Press.

Chevrier, S. (2003). Cross-cultural management in multinational project groups. Journal of World Business, 38(2), 141-149.

Chiarini, A., Baccarani, C., and Mascherpa, V. (2018). Lean production, Toyota Production System and Kaizen philosophy: A conceptual analysis from the perspective of Zen Buddhism. The TQM Journal, 30(4): 425-438.

D'Costa, Anthony P. (2003) "Institutions and industrial governance in India: Learning to cooperate the Japanese way." Asian Business \& Management 2(1): 63-89.

Invest India (2020) https://www.investindia.gov.in/team-india-blogs/how-japanese-companieshave-made-home-india, accessed 24.10.2020

Earley, P. C. (2006). Leading cultural research in the future: A matter of paradigms and taste. Journal of International Business Studies, 37(6), 922-931.

Fornell, C., Morgeson III, F. V., and Hult, T. M. (2016). Stock returns on customer satisfaction do beat the market: gauging the effect of a marketing intangible. Journal of Marketing, 80(5), 92-107

Garcia, D., and Gluesing, J. C. (2013). Qualitative research methods in international organizational change research. Journal of Organizational Change Management, 26(2), 423444

Griffin, A. and Hauser, J.R. (1993). The voice of the customer. Marketing Science, 12:1-27.

Hall, E. T. (1960). The silent language in overseas business. Harvard business review, 38(3):8796.

Hambrick, D. C. (2007). The field of management's devotion to theory: Too much of a good thing?. Academy of Management Journal, 50(6):1346-1352.

Haron, H., Ismail, I., and Oda, S. (2015). Ethics, Corporate Social Responsibility and the use of Advisory Services provided by SMEs: Lessons learnt from Japan. Asian Academy of Management Journal, 20(4): 947-952.

Hatvany, N., and Pucik, V. (1981). An Integrated Management System: Lessons from the Japanese Experience. Academy of Management Review, 6(3), 469-480. 
Haynes, K. (2011). Tensions in (re) presenting the self in reflexive autoethnographical research. Qualitative Research in Organizations and Management: An International Journal, 6(2), 134-149

Hennig-Thurau, T. (2004). Customer orientation of service employees: Its impact on customer satisfaction, commitment, and retention. International Journal of Service Industry Management, 15(5), 460-478.

Hofstede, G. (1983). The Cultural Relativity of Organizational Practices and Theories. Journal of International Business Studies, 14(2), 75-89.

Hosoda, M. (2018). Management control systems and corporate social responsibility: perspectives from a Japanese small company. Corporate Governance: The International Journal of Business in Society, 18(1): 68-80.

Kazmi, A. (2009). Strategic Management and Business Policy. New Delhi: Tata McGraw Hill.

Khalifa, A. S. (2004). Customer value: a review of recent literature and an integrative configuration. Management Decision, 42(5), 645-666.

King, N. (2004) 'Using Interviews in Qualitative Research', in C. Cassell and G. Symon (eds) Essential Guide to Qualitative Methods in Organizational Research, pp. 1122. London: SAGE.

Knights, D., \& Willmott, H. (1999). Management Lives: Power and Identity in Work Organizations. Sage.

Kohli, A. K., and Jaworski, B. J. (1990). Market orientation: the construct, research propositions, and managerial implications. The Journal of Marketing, 54(2):1-18.

Kordupleski, R.T. and Laitamaki, J. (1997), "Building and deploying profitable growth strategies based on the waterfall of customer value added" ,European Management Journal, 24(2): 158-166.

Kumar, V., and Reinartz, W. (2016). Creating enduring customer value. Journal of Marketing, 80(6): 36-68.

Kumar, M. R., Sahay, B. K., and Ranjan, P. (2011). Adapting TQM to change Indian bureaucracy: A view from inside. Quality Management Journal, 18(1): 23-38 
Kumar, V., Aksoy, L., Donkers, B., Venkatesan, R., Wiesel, T., \& Tillmanns, S. (2010). Undervalued or overvalued customers: capturing total customer engagement value. Journal of Service Research, 13(3): 297-310.

Lander, E., \& Liker, J. K. (2007). The Toyota Production System and art: making highly customized and creative products the Toyota way. International Journal of Production Research, 45(16), 3681-3698.

Malterud, K., Siersma, V. D., and Guassora, A. D. (2016). Sample size in qualitative interview studies: guided by information power. Qualitative Health Research, 26(13), 1753-1760.

Mahajan, G. (2016). Value Creation, the Definitive Guide for Business Leaders. Los Angeles: Sage.

Mahajan, M. P., and Sekiguchi, T. (2016). The Influence and Effectiveness of US-style and Japanese-style HR Practices on Indian Firms: A Conceptual Perspective. South Asian Journal of Human Resources Management, 3(1): 58-74.

Mathur, B. P. (2016). An Alternative Philosophy of Development: From Economism to Human Well-being. Routledge India.

Melville, I. (2000). Marketing in Japan. Oxford: Butterworth-Heinemann.

Moore, N and Stokes, P. (2012) Elite Interviewing and the role of Sector Context: An Organizational Case form the Football Industry, Qualitative Market Research: An International Journal, 15(4): 438-464.

Morgan, J., \& Liker, J. K. (2020). The Toyota product development system: integrating people, process, and technology. CRC Press.

Narver, J. C., and Slater, S. F. (1990). The effect of a market orientation on business profitability. The Journal of Marketing, 54(4): 20-35.

Patel, T. (2016). Promoting multi-paradigmatic cultural research in international business literature: An integrative complexity-based argument. Journal of Organizational Change Management, 29(4): 599-629.

Patel, T. (2017). Multiparadigmatic studies of culture: Needs, challenges, and recommendations for management scholars. European Management Review, 14(1): 83-100.

Romani, L., Barmeyer, C., Primecz, H., and Pilhofer, K. (2018). Cross-cultural management studies: state of the field in the four research paradigms. International Studies of Management \& Organization, 48(3): 247-263. 
Romani, L., Mahadevan, J., and Primecz, H. (2018). Critical cross-cultural management: Outline and emerging contributions. International Studies of Management \& Organization, 48(4): 403-418.

Ronen, S., and Shenkar, O. (2013). Mapping world cultures: Cluster formation, sources and implications. Journal of International Business Studies, 44(9): 867-897.

Sackmann, S. A. (2020). Culture in Cross-Cultural Management: Its Seminal Contributors from a Positivist. The SAGE Handbook of Contemporary Cross-Cultural Management, 17.

Saranga, H, Mudambi, R and Schotter, A (2017) Mastering the Make-in-India Challenge. MIT Sloan Management Review; Cambridge 58.4(Summer 2017): 59-66.

Schedlitzki, D., Ahonen, P., Wankhade, P., Edwards, G., and Gaggiotti, H. (2017). Working with Language: A Refocused Research Agenda for Cultural Leadership Studies. International Journal of Management Reviews, 19(2): 237-257.

Schwartz, S. H. (1999). A Theory of Cultural Values and Some Implications for Work. Applied Psychology, 48(1): 23-47.

Sorescu, A., and Sorescu, S. M. (2016). Customer satisfaction and long-term stock returns. Journal of Marketing, 80(5): 110-115.

Sparrow, P. R., and Budhwar, P. S. (1997). Competition and change: Mapping the Indian HRM recipe against world-wide patterns. Journal of World Business, 32: 224-242

Srinivas, N. (2012). Epistemic and performative quests for authentic management in India. Organization, 19(2): 145-158.

Stokes, P. (2011). Critical concepts in management and organization studies. Palgrave Macmillan.

Terpstra, M., and Verbeeten, F. H. (2014). Customer satisfaction: Cost driver or value driver? Empirical evidence from the financial services industry. European Management Journal, 32(3): 499-508.

Trompenaars, A., and Hampden-Turner, C. (2012). Riding the Waves of Culture: Understanding Diversity in Global Business. London: Nicholas Brealey Publishing.

Tsui, A. S., Nifadkar, S. S., and Ou, A. Y. (2007). Cross-national, cross-cultural organizational behavior research: Advances, gaps, and recommendations. Journal of Management, 33(3), 426-478. 
Turpin, D. (1994), Reaching the heart and mind of the customer: Japan's best practices in customer service, Journal of Strategic Change, 3(6): 323-7.

Urry, J., \& Larsen, J. (2011). The Tourist Gaze 3.0., London, Sage Publications.

Vargo, S. L., and Lusch, R. F. (2008). Service-dominant logic: continuing the evolution. Journal of the Academy of Marketing Science, 36(1): 1-10.

Vaiman, V., and N. Holden. 2015. "Cross-Cultural Management. Arguing the Case for NonCultural Explanations." In The Routledge Companion to Cross-Cultural Management, edited by N. Holden, S, Michailova, and S. Tietze, 58-67. London, UK: Routledge

Webster Jr, F. E. (1988). The rediscovery of the marketing concept. Business Horizons, 31(3), 29-39.

Welch, C., and Piekkari, R. (2006). Crossing language boundaries: Qualitative interviewing in international business. Management International Review, 46(4): 417-437.

Willmott, H. (2005). Theorizing contemporary control: Some post-structuralist responses to some critical realist questions. Organization, 12(5): 747-780.

Willmott, H. (2011). Journal list fetishism and the perversion of scholarship: reactivity and the ABS list. Organization, 18(4): 429-442

Woodruff, R.B. (1997), “Customer value: the next source for competitive advantage" , Journal of the Academy of Marketing Science, 25(2): 139-53.

Zinser, B. A., and Brunswick, G. J. (2016). The Evolution of Service-Dominant Logic and It's Impact on Marketing Theory and Practice: A Review. Academy of Marketing Studies Journal, 20(2): 120. 
Figures

Figure 1: Customer value orientation

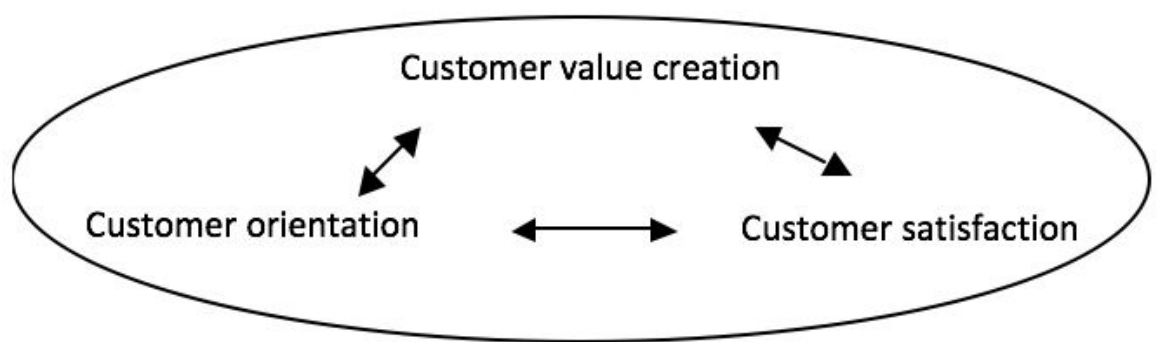

Figure 2: Contribution to CCM scholarship

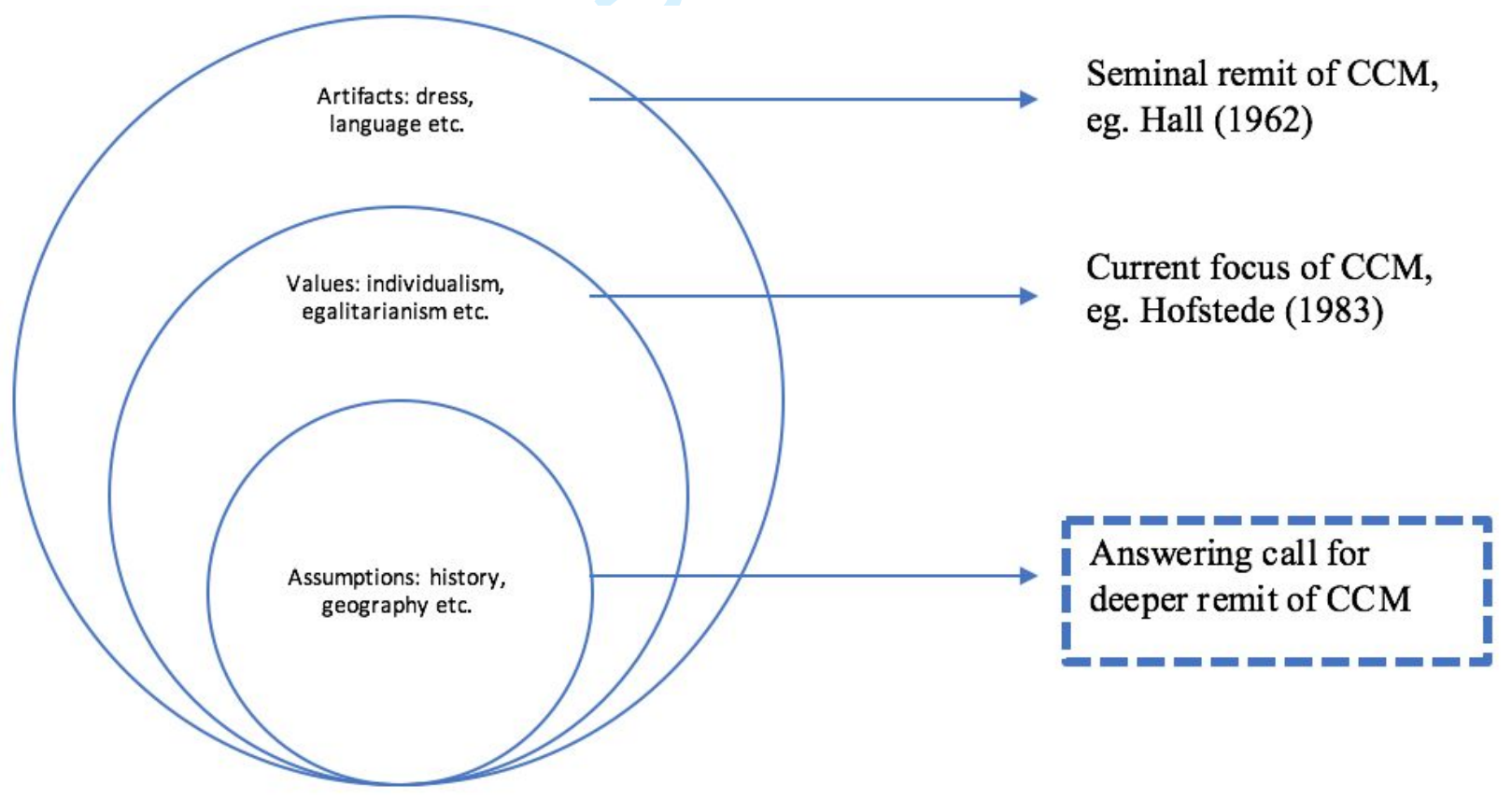

Author's diagram (2020): adapted representation of Nested Spheres Model of Culture

(Trompenaars and Hampden-Turner, 2012) 
Figure 3: Contribution to India-Japan international business dyad CVO scholarship (crosscultural commonalities)

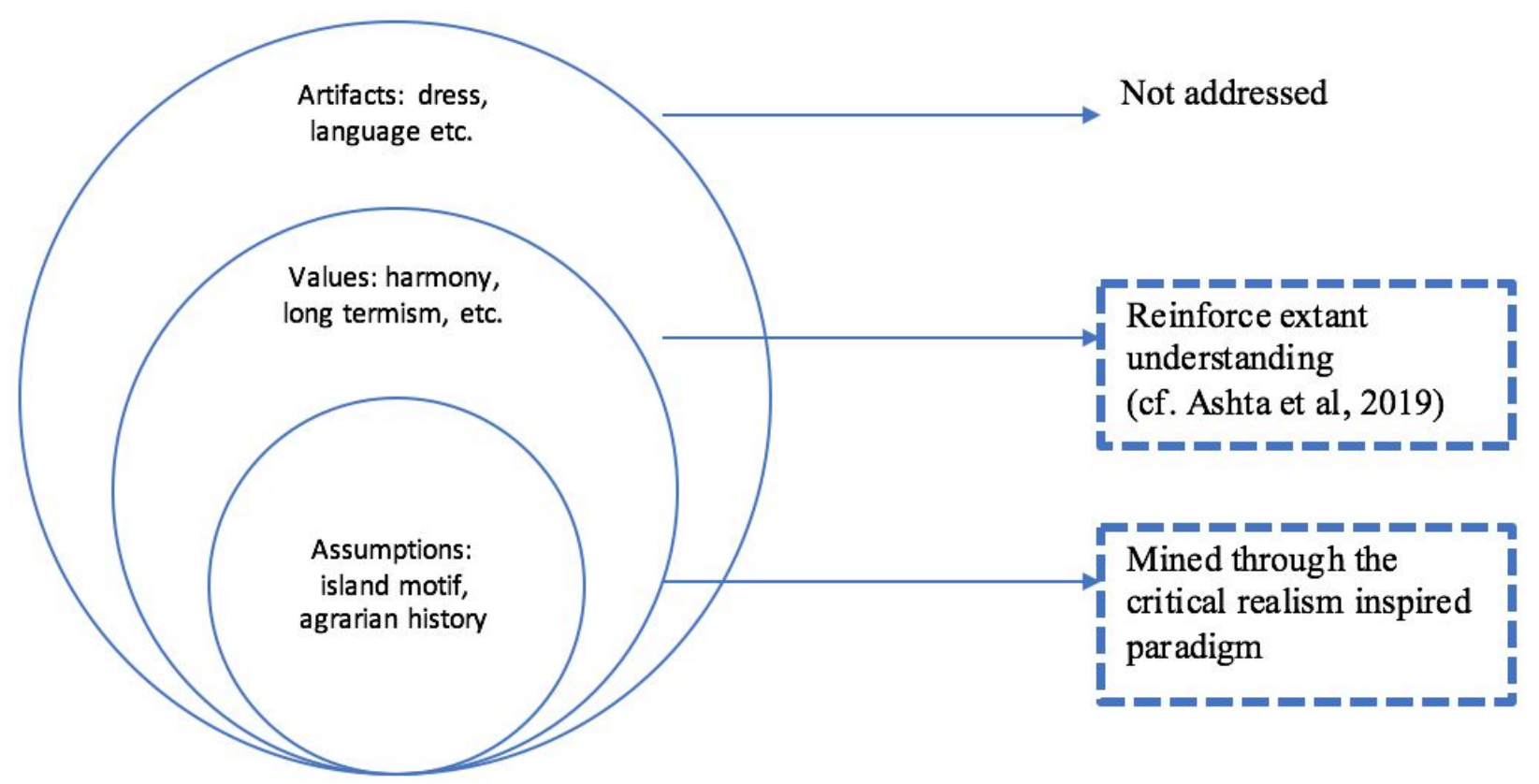

Author's diagram (2020): adapted representation of Nested Spheres Model of Culture

(Trompenaars and Hampden-Turner, 2012) 